uptake of iodine by the human thyroid gland, agreement is again reasonably good. It is difficult to see how, within the limits set by the SMALL BOY data, Dr. Knapp could have come up with any better conclusions.

The relationship between the level of $\gamma$-radiation measured above the ground surface and the amount of iodine-131 per unit area of that surface varies enormously with the composition of the deposited material. The transfer of iodine-131 to milk is affected by such diverse factors as the chemical and physical form of the fall-out, which govern the behaviour of the deposited material on herbage and the biological availability of the iodine, and the animal management practised by local farmers. Unless allowance can be made for divergence of these and other variables from Dr. Knapp's norms, extrapolation of his relationship to other situations, although tempting, is not admissible. Dr. Knapp is aware of and discusses these sources of error particularly in the context of some of the earlier Nevada test firings made at a time when milk was not analysed for iodine-131. Although he does not say so explicitly, Dr. Knapp strongly hints that children in the area surrounding the Nevada test site could have received much higher radiation doses to their thyroid glands from iodine-131 in milk than had been suspected. This surmise is supported by independent investigations carried out by the University of Utah and, as might be expected, the report has aroused considerable public interest in the United States. However pessimistic Dr. Knapp's deductions, they must leave the responsible authorities with an uncomfortable feeling that all doubts might have been resolved had milk been examined. Milk is now well recognized as the predominant vehicle for transfer of many nuclides, including iodine-131, to man in the Western countries. Dr. Knapp's report points the moral that, although estimation of levels of iodine-131 on the ground surface - or in the air-allows prediction of levels in milk, it does so only inaccurately and that it is wiser and more profitable to examine milk itself. This is a lesson, let it be said, that does not need to be taught to those responsible for surveys for radioactivity in the environment in Britain.

\section{R. J. Garner}

\title{
ABORIGINES IN AUSTRALIA
}

\begin{abstract}
A SPECIAL issue of Australian Natural History (14, No. 8: The Australian Museum, Sydney, 1963) is devoted to the history, culture and present status of the Aborigines. According to W. R. Browne, changes in climate during the Quaternary period, the effects of which are so conspicuous in the northern hemisphere, extended to all parts of the world. When the accumulations of ice around the poles were at their maximum the level of the oceans was lowered $300 \mathrm{ft}$. or more with corresponding extensions to the land areas. It was under such conditions that the first human beings reached Australia, perhaps about 20,000 years ago. The climate then was cooler and wetter than it is now, and giant forms of marsupials were in the country, but which have now become extinct.
\end{abstract}

N. W. G. Macintosh believes that the migrants came from south-east Asia, but that they must have been seafaring people since they had to cross both Wallace's and Weber's lines, which have marked areas of deep water for at least 75 million years. The evolutionary history of these people remains an open question. The most likely view is that they have descended through types like Pithecanthropus, Homo soloensis and Homo sapiens wadjakensis, remains of which have been found in Java. There are also suggestions that a certain amount of admixture with Negritoid, Caucasian, and pre-Dravidian stocks may also have occurred. In confirmation of such views, up to the present, finds of fossil evidence have been scanty, and their precise dating has proved difficult.

The Talgai cranium was discovered in Queensland in 1886, the Cohuna skull was found in Victoria in 1925, and in 1960 the Mossgiel skeleton was discovered, in New South Wales. This last-mentioned find closely resembles $H$. soloensis, and while massive, all three skulls differ only in minor details from those of modern Aborigines, and all possess certain primitive characteristics. A more problematic variant is the Keilor cranium, found near Melbourne in 1940. In shape and structure it is distinctly more modern than the others. So far, it has not been dated with certainty, but it would seem to go back for about 13,000 years, a fact which raises difficulties in attempts to fit it into any line of hominid evolution. Blood group tests indicate that Australian Aborigines differ on significant points from present-day Melanesians; and investigations of their dermatoglyphics show that while some similarities exist between those of the Aborigines and Melanesians, the patterns differ markedly from European, Ainu and African Pigmy types; their closest affinitios are to be found among the Mongols.
According to Thérèse Belleau Kemp, the number of original native inhabitants of Tasmania was small. Archæological evidence reveals that almost certainly they reached the Island by way of Australia. They suffered at the hands of the European settlers, who drove them from their hunting places and best sources of food. In 1829 those who remained were removed to Flinders Island, where, six years later, they numbered 200. By 1847 , the total was reduced to 40 , and the last of them died in 1876. The industries and culture of these people were similar to those on the Australian mainland; but while the people on the east coast and midlands lived by food-gathering and hunting, groups on the west coast fed mainly on land marsupials and sea mammals. They were highly skilled in fashioning stone tools. Why they died out so rapidly remains a matter of opinion. It might seem as if they were poorly endowed with natural defences against diseases, like tuberculosis, brought in by people from overseas.

The prehistory of the Australian Aborigines is reviewed by F. D. McCarthy. While fossil human remains are scarce, evidence of aboriginal industries and ways of life is relatively abundant, indicating that, as a whole, cultural practices were comparable with those in Europe at the time of overlap between the upper Palrolithic and Neolithic periods. In sites along the Murray River, some of the characteristic stone tools in order of antiquity were the tula, a flake with a convex working edge, and the pirri, a spear point chipped on one surface; and in eastern New South Wales, Bondi points, elegantly made for spears and barbs, and the elouera, a ground edge used for knives and axes. Some of the tools were hafted. An industry based on finely worked microliths was once widely spread, but eventually it died out altogether. As a whole, however, the industries display only slight variations, and middens provide evidence that some sites were occupied by Aborigines for generation after generation, perhaps for as long as 10,000 years, with a minimum of change in the general way of life.

A considerable number of rock engravings have also been discovered. They are most common in the SydneyHawkesbury district of eastern New South Wales, the Flinders Ranges of South Australia, the Carnarvon and other ranges in south-eastern Queensland, and many localities in north-western Australia. A beginning has been made in their recording and classification. Of engravings, probably the oldest phase consists of grooves rubbed into the rock surface, forming simple parallel 
sets, radiate and other patterns. Another phase is represented by outline tracings of mythical figures, animals, weapons and human beings. A third type comprises lines arranged in concentric circles, grids, meanders, etc. In a fourth phase there was a return to naturalism, with representations of human beings and animals, weapons and sacred objects, some life-size, others in miniature. The publication contains a selection of fine photographs of some of these works of art, including a particularly striking life-size stencil of a human being with arms outstretched, which was discovered in Queensland.

Of cave paintings there are many thousands, scattered all over the continent, most of them still awaiting detailed investigation. The earliest kind appear to consist of simple stencil outlines of many objects, sometimes associated with figures drawn in one colour as silhouettes. Later, divergences appeared in various parts of the country based on the use of two or more colours, and taking the form of more elaborate figures, which in Arnhem Land developed into depictions of animals and decorative human figures, with emphasis on their internal structures, especially those parts concerned with sex.

A. P. Elkin discusses the present status of the Aborigines. He points out that when in sole occupation of the continent, they possessed a social organization which ensured order in the search for a livelihood and access to hunting areas, and that through their myths and rituals they sought adjustment to the contingencies of life and death. All this was delicately poised. Through seizure of their land by immigrant settlers, their economic and cultural life was disrupted and those who remained became pauperized hangers-on around the new communities. Their diet deteriorated. Only in the more arid and less-fertile areas had they time to make some kind of an adjustment.

From 1860 onwards, schemes for their protection began to be put into effect, but at first the policies had little positive result. Only in the 1920 's were more constructive plans introduced with the view of improving their welfare and assimilation. As a consequence, depopulation has come to an end, and now the Aborigines number about 40,000. They enjoy the rights of ordinary eitizenship, yet many are hesitant about leaving the protected life of Government settlements and facing the hazards and responsibilities of contemporary economic and social activity, seeking regular, paid employment and making a full adaptation to Australian society. All the same, a growing number of the children are passing through secondary schools; some are training to be nurses and teachers, and a few have reached the universities. Full merging and assimilation into Australian life appear to be the final outcome, particularly since there are about 52,000 mixed-blood Aborigines already in the country.

\title{
FRACTIONATION OF BASALT MAGMAS AT HIGH PRESSURES
}

\author{
By Dr. D. H. GREEN and Prof. A. E. RINGWOOD \\ Department of Geophysics, Australian National University, Canberra
}

\begin{abstract}
LTHOUGH basalts seem to exhibit a continuous A spectrum of chemical compositions, combined petrographic and chemical studies have led to the general recognition of two magma types, alkali basalt and tholeiitic basalt, with their respective differentiation series ${ }^{1}$. The tholeiitic suite is characterized by the presence of normative hypersthene and modal hypersthene or pigeonite, while the alkali basalt suite is characterized by normative olivine with nepheline and modal high-CaO augite or titan-augite ${ }^{1}$. In the tholeiitic suite, fractionation at low pressure is dominated by early crystallization of olivine and by the reaction relationship of magnesian olivine to orthopyroxene. Fractional crystallization at low pressures leads to an increase in the silica saturation of the residual liquid. In the alkali basalt suite, crystallization of olivine with $\mathrm{CaO}$-rich clinopyroxene continues the state of critical undersaturation in silica in the early stages of fractionation.
\end{abstract}

From examination of natural cases of differentiation in the crust and from experimental investigations, there appears to be no plausible way in which an alkali basalt liquid could be derived from a parental tholeiitic liquid, or vice versa, by processes of fractional crystallization at low pressure. However, Yoder and Tilley ${ }^{1}$ have shown that, at pressures of $20 \mathrm{~kb}$. and greater, crystallization in a variety of basaltic compositions is dominated by the phases pyrope-almandine garnet and omphacitic clinopyroxene. They have suggested that the position of a co-tectic between these two phases may be pressure sensitive and thus that fractional melting of garnet peridotite at different pressures could produce the two magma suites. Yoder and Tilley also suggested that separation of garnet from a primitive basalt liquid would leave a liquid typical of the alkali basalt suite, whereas separation of omphacite would leave a liquid crystallizing at low pressures as a member of the tholeiitic suite.

As an alternative hypothesis Powers ${ }^{2}$, Tilley ${ }^{3}$ and Macdonald ${ }^{4}$ have discussed the possibility that the field of primary crystallization of orthopyroxene from tholeiitic magma might be substantially increased by high pressure. Excess crystallization of orthopyroxene could move the residual liquid into the critically undersaturated field of the alkali basalt. Our experimental results support this latter hypothesis.

The preliminary experiments reported here are in the intermediate pressure range, $10-20 \mathrm{~kb}$. The experiments have been carried on a basalt composition very close to the estimate by Macdonald and Katsura ${ }^{5}$ of the "parent magma' for olivine tholeiite from Kilauea Iki.

Experimental runs were made in a single-stage highpressure apparatus of the type designed by Boyd and England ${ }^{6}$. The basalt mixture was fused to a glass, finely ground, dried over iron powder and re-analysed for $\mathrm{FeO}$ and $\mathrm{Fe}_{2} \mathrm{O}_{3}$ to check the oxidation state. The sample was loaded into a platinum capsule and compressed in a pellet press. The sample was brought to the desired pressure, and the temperature quickly raised and held at the desired value for one hour. The run was quenched to about $200^{\circ} \mathrm{C}$ in less than 30 sec by switching off power to the furnace. Quenching yielded glass with variable amounts of quench clinopyroxene. The capsules were not sealed by welding in these initial runs and in all cases there has been access of small amounts of water from dehydration of the talc pressure medium. Because of this effect our temperatures are appreciably lower than the liquidus temperatures for similar dry basalt compositions ${ }^{1,7}$.

Following Boyd and England ${ }^{8}$, no corrections have been made for friction, and pressure determinations are believed to be accurate to \pm 5 per cent in an absolute sense and in a relative sense, comparing run to run, to better than 2 per cent. Temperature measurement by platinumplatinum 10 per cent rhodium thermocouple is estimated to be accurate to $\pm 10^{\circ} \mathrm{C}$ with a variation of $\pm 5^{\circ} \mathrm{C}$ about the control point.

Parts of the sample were powdered and examined optically and by $\mathrm{X}$-ray diffraction. In partial melting runs olivine, enstatite, garnet and clinopyroxene are readily recognized from their optical properties and also 